Hydrol. Earth Syst. Sci., 17, 3059-3075, 2013

www.hydrol-earth-syst-sci.net/17/3059/2013/

doi: 10.5194/hess-17-3059-2013

(c) Author(s) 2013. CC Attribution 3.0 License.

\title{
Characterizing floods in the poorly gauged wetlands of the Tana River Delta, Kenya, using a water balance model and satellite data
}

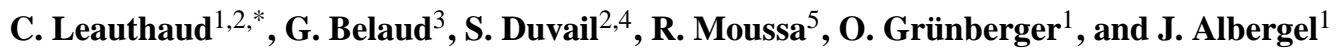 \\ ${ }^{1}$ IRD, UMR LISAH, 34060 Montpellier, France \\ ${ }^{2}$ Kenya Wetland Biodiversity Research Team (KENWEB), Nairobi, Kenya \\ ${ }^{3}$ SupAgro, UMR G-eau, B.P. 5095, 34196 Montpellier, France \\ ${ }^{4}$ IRD, UMR PALOC, 75005 Paris, France \\ ${ }^{5}$ INRA, UMR LISAH, 34060 Montpellier, France \\ *Invited contribution by C. Leauthaud, recipient of the EGU Outstanding Student Poster Award 2012.
}

Correspondence to: G. Belaud (belaud@ supagro.inra.fr)

Received: 12 September 2012 - Published in Hydrol. Earth Syst. Sci. Discuss.: 4 October 2012

Revised: 25 June 2013 - Accepted: 25 June 2013 - Published: 1 August 2013

\begin{abstract}
Wetlands, such as those of the Tana River Delta in Kenya, are vital but threatened ecosystems. The flooding characteristics of wetlands largely determine their physical, chemical and biological properties, so their quantification is crucial for wetland management. This quantification can be achieved through hydrological modelling. In addition, the analysis of satellite imagery provides essential hydrological data to monitor floods in poorly gauged zones.

The objective of this study was to quantify the main water fluxes and flooding characteristics (extent, duration and number of floods) in the poorly gauged Tana River Delta in East Africa during 2002-2011. To do so, we constructed a lumped hydrological model (the Tana Inundation Model, TIM) that was calibrated and validated with MODIS data. Further analysis of the MYD09A1 $500 \mathrm{~m}$ composite product provided a map of the empirical probability of flooded state. In non-extreme years and for the current topology of the delta, the flood extent exceeded $300 \mathrm{~km}^{2}$. Floods over $200 \mathrm{~km}^{2}$ occurred on average once a year, with a mean duration of 18 days. River discharge from the upper basin counted for over $95 \%$ of the total water inflow. The results are discussed in the light of possible improvements of the models and wetland management issues.

This study provides the first known quantification of spatial and temporal flooding characteristics in the Tana River Delta. As such, it is essential for the water and natural resource management of the Tana River basin. The water balance approach was pertinent to the study of this system, for
\end{abstract}

which information on its internal properties and processes is limited. The methodology, a combination of hydrological modelling and flood mapping using MODIS products, should be applicable to other areas, including those for which data are scarce and cloud cover may be high, and where a medium spatial resolution is required.

\section{Introduction}

Wetlands are increasingly recognized as ecosystems that are essential to human activities (Mitsch and Gosselink, 2000) because they provide a wide range of ecosystem services (Daily, 1997; Millennium Ecosystem Assessment, 2005). However, they are amongst the most threatened ecosystems worldwide (Vitousek et al., 1997). Their extent is rapidly declining, with an estimated decrease in the global average maximum inundated area of $6 \%$ from 1993 to 2007 (Prigent et al., 2012).

Modifications in up-stream land use, hydro-electric infrastructure, and increased water withdrawal, in conjunction with climate change, are considered to be the main factors modifying the flooding characteristics of wetlands. In particular, dam construction has altered many wetlands throughout Africa, such as those of the Senegal River Delta in Mauritania (Duvail and Hamerlynck, 2003) and in Senegal (Lamagat et al., 1996; Bader et al., 2003), the Inner Delta of the Niger River in Mali, the Waza Logone in Cameroon (Loth, 
2004), the Medjerda River in North Africa (Zahar et al., 2008), the Tana River in Kenya (Maingi and Marsh, 2002) and the Hadejia-Jama' are floodplains in Nigeria (Barbier and Thompson, 1998), while many others are threatened such as the Okavango Delta in Botswana (Milzow et al., 2009) and the Rufiji Delta (Duvail and Hamerlynck, 2007).

The flooding characteristics of wetlands, particularly the flood extent, timing, frequency, duration and flood peaks, largely determine the physical, chemical and biological properties of wetlands (Mitsch and Gosselink, 2000). Their quantification is therefore crucial for the management of wetlands and can be achieved through hydrological modelling.

Many types of flood models exist, ranging from lumped to distributed models. They mainly differ in their physical basis, complexity and data requirements. Distributed models are generally used when accurate data are available, while conceptual models are better suited to poorly gauged sites where data acquisition is difficult.

In recent years, there has been a rapid development of distributed models due to the proliferation of high-quality quantitative data (e.g. topography, remote-sensing imagery) and increasing computational power (Hunter et al., 2007). However, data, end-user and computational constraints also need to be considered (Beven and Freer, 2001). Furthermore, hydro-dynamic modelling of river-floodplain systems must be undertaken with precaution in large and flat floodplains, where small uncertainties in the water level can generate large errors in the prediction of flood extents.

For these reasons, more parsimonious approaches using simplified assumptions, have recently (re-)emerged in the scientific literature. In particular, lumped models combined with remote-sensing data have been used to characterize flood extents in poorly gauged and poorly characterized wetlands, such as the Okavango Delta (Wolski et al., 2006), and the Inner Delta of the Niger River (Mahe et al., 2011).

Remote sensing data can be used to detect water bodies and their characteristics (water extent, level, vegetation cover, sediment load, etc.) for calibration and validation of hydrological models. However, there are no standard methods to do so. Synthetic Aperture Radar imagery is very popular because of its high spatial resolution (e.g. a pixel size of $12.5 \mathrm{~m}$ for ERS-1 PRI data) and its capacity to map water under thick vegetation. However, the radar signals are sensitive to wind-induced waves, especially in the C-band, limiting the usefulness of this band for water detection (Alsdorf et al., 2007). L-band data are limited by their low orbital repeat cycles, cost and limited archives. Passive microwave data have been used to detect flood extents (Sippel et al., 1998; Ticehurst et al., 2009) but are also limited by a low spatial resolution. Thermal satellite data have been used to map inundated areas (Leblanc et al., 2011), but to our knowledge, these data have an inadequate monthly timescale for characterizing rapidly changing flood extents. An alternative solution is the use of passive optical/infrared sensors on board the Landsat, Aqua, Terra or SPOT satellites.
The MODIS instruments on-board the Terra and Aqua satellites have been providing daily data for 36 spectral bands between 0.405 and $14.385 \mu \mathrm{m}$ at a $250 \mathrm{~m}$ to $1 \mathrm{~km}$ resolution since 2000 and 2002, respectively. They have been used to characterize water levels (Ordoyne and Friedl, 2008), the seasonality of lake systems (Feng et al., 2012), the extent of annual flooding (Sakamoto et al., 2007) and to map wetlands and flooding patterns (Ticehurst et al., 2009; Islam et al., 2010). MYD09A1 is a level-3 high-quality composite product, with a $500 \mathrm{~m}$ resolution. Each pixel contains the best possible observation during an 8-day period, corrected for atmospheric gases and aerosols, and is hence useful in zones subject to high cloud cover. Furthermore, two bands describe the quality of each pixel regarding aerosols and the presence of clouds or cloud shadow so that masking poor quality pixels is possible. Despite their moderate resolution, the long-term data collection and frequent overpasses make this product a good candidate for monitoring large- to medium-sized wetland complexes.

The objective of this study was to quantify the main water fluxes and flooding characteristics in a poorly gauged East African wetland, the Tana River Delta (TRD). To do so, we constructed a lumped hydrological model (the Tana Inundation Model, TIM) that allowed us to determine the role of river fluxes in flooding events and the number of flood events from 2002 to 2011 and to characterize the extent and duration of these floods. Satellite data were used to calibrate and validate the model, and to provide a spatial representation of the flooded zones. The hydrological variables quantified in this study are relevant for the management of the wetlands. After a description of the TRD, focusing in particular on its hydrological characteristics, the MODIS satellite data are analyzed, and the Tana Inundation Model is presented. Finally, the results are described in detail and then discussed in the light of wetland management issues.

\section{The Tana River Delta, Kenya}

\subsection{Socio-economic and environmental context}

The Tana River Delta (TRD, Fig. 1) is located on the Kenyan coast between the towns of Garsen, Lamu and Malindi and extends roughly over $1300 \mathrm{~km}^{2}$. The region is among the poorest in Kenya and its indicators of human well-being are extremely low (United Nations Development Programme, 2010). The local population (over 100000 inhabitants) is predominantly from the Pokomo, Orma, Somali, Wardei and Wata communities (Republic of Kenya, 2010), and they mainly rely on farming, fishing and livestock-keeping activities for their subsistence (Leauthaud, 2009; Duvail et al., 2012; Leauthaud et al., 2013). In addition to the economical and human value of the TRD, its complex landscape mosaic has an exceptional biodiversity value (Hamerlynck et al., 2012). 


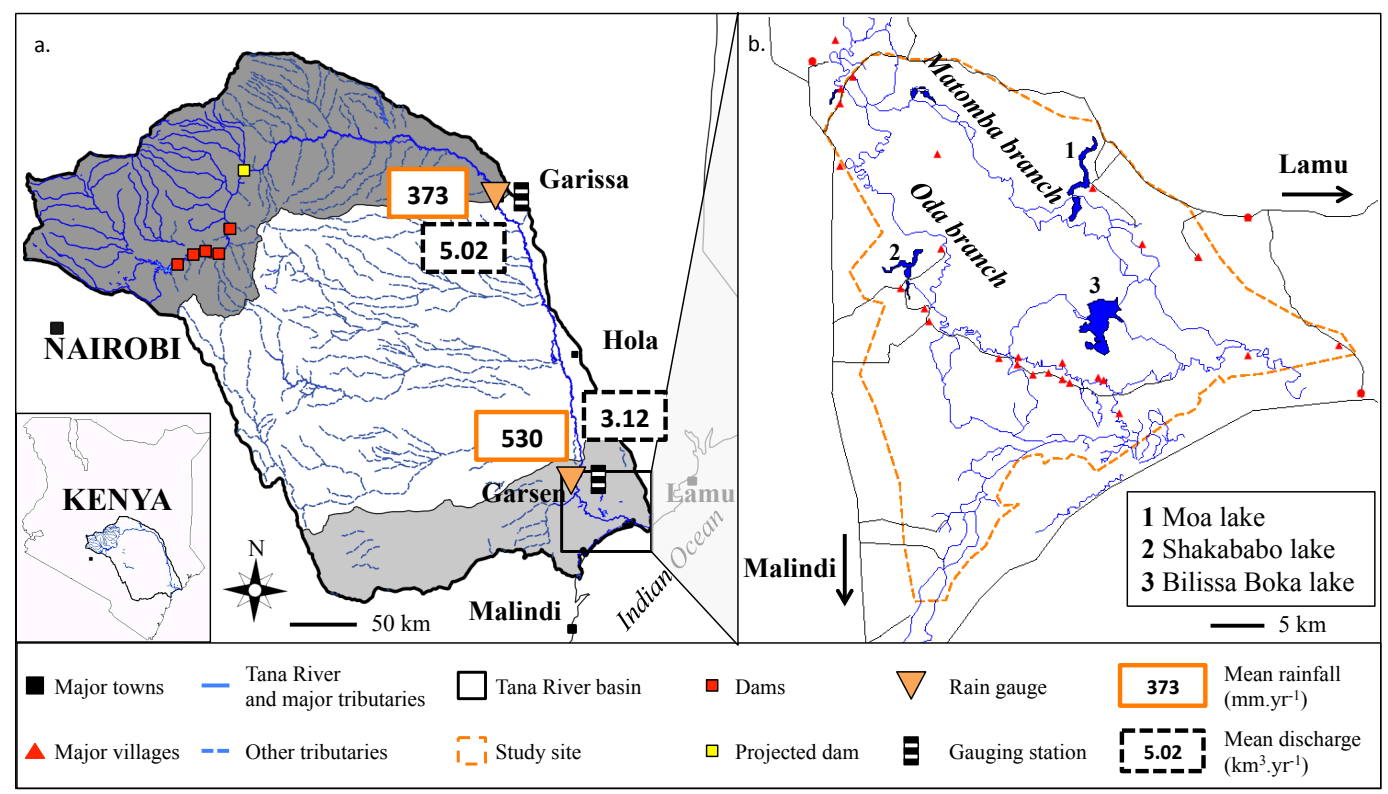

Fig. 1. (a) The Tana River basin and its main hydrological characteristics. The location of the precipitation and discharge data used for this study are specified. The sub-basins before the Garissa and after the Garsen gauging stations are presented in dark and light grey, respectively. (b) The Tana River Delta, its major channels, lakes, villages and roads.

Over the past fifty years, five major reservoirs have been built in the upper basin that have significantly modified the hydrological regime of the river, with a $20 \%$ decrease in the peak flows of May (Maingi and Marsh, 2002). Other projects, particularly those of the Grand Falls Dam, could further impact the downstream flooding processes in the near future. In recent years, many biofuel and large irrigation schemes have also been initiated that will deprive the local communities of essential land and water resources (Duvail et al., 2012). It is therefore important to quantify current river water resources within the delta.

\subsection{Basin characteristics and data constraints for hydrological modelling}

The Tana is the largest river in Kenya and flows over nearly $1000 \mathrm{~km}$ from Mount Kenya and the Aberdare Mountains to the Indian Ocean. Its flowing pattern is bi-modal, with peak flows occurring during the long and short rainy seasons. Long-term discharge data were available at three locations within the Lower Tana Catchment. The closest longterm and active gauging station is at Garissa $\left(0^{\circ} 27^{\prime} 49.19^{\prime \prime} \mathrm{S}\right.$, $39^{\circ} 38^{\prime} 11.77^{\prime \prime} \mathrm{E}, 1941$-current), which is located $250 \mathrm{~km}$ upstream of the TRD. Two other gauging stations were located at Hola $\left(1^{\circ} 30^{\prime} 00.00^{\prime \prime} \mathrm{S}, 40^{\circ} 02^{\prime} 00.17^{\prime \prime} \mathrm{E}, 1949-1991\right)$ and Garsen ( $\left.2^{\circ} 16^{\prime} 09.36^{\prime \prime} \mathrm{S}, 40^{\circ} 07^{\prime} 16.32^{\prime \prime} \mathrm{E}, 1950-1998\right)$; however they are no longer monitored, and their data are discontinuous ( 22.8 and $41.2 \%$ of gaps in record, respectively). Maximum peak discharges in Garissa were $1622 \mathrm{~m}^{3} \mathrm{~s}^{-1}$ in 1941 and then $1585 \mathrm{~m}^{3} \mathrm{~s}^{-1}$ in 1961.
Maingi and Marsh (2002) consider flood propagation and losses due to evaporation to be the major hydrological processes that occur within the semi-arid stretch between Garissa and Garsen. This consideration is supported by three facts:

1. a rapid analysis of river discharges at Garissa and Garsen shows that peak discharge rates are largely attenuated and smoothed out between the two stations (Fig. 2), with an average decrease in transiting volume of $76 \%$ (Table 1);

2. only seasonal rivers, such as Laga Tula, the Laga Galole and the Laga Tiva, flow into the Tana River within this stretch;

3. with a hypothetical water requirement of $2 \mathrm{~L} \mathrm{~s}^{-1} \mathrm{ha}^{-1}$ and a cultivated area of 4000 ha, water abstraction at the Bura and TDIP irrigation schemes would not significantly alter the Tana River discharge during peak flows and hence the flooding characteristics in the TRD.

The precipitation decreases from the coast at Malindi $\left(1098 \pm 306 \mathrm{~mm} \mathrm{yr}^{-1}, 1962-2008\right)$ to the inlands $\left(530 \pm 202 \mathrm{~mm} \mathrm{yr}^{-1}\right.$ in Garsen, 1972-1986, data from the Kenya Meteorological Department, KMD, Kenya. Years with over one month of missing data were excluded). The rainfall pattern is bi-modal, with two rainy seasons extending from April to June and from November to December, both of which correspond to the flooding periods for the Tana River in natural conditions. Recent daily precipitation and minimum and maximum daily air temperatures for the 


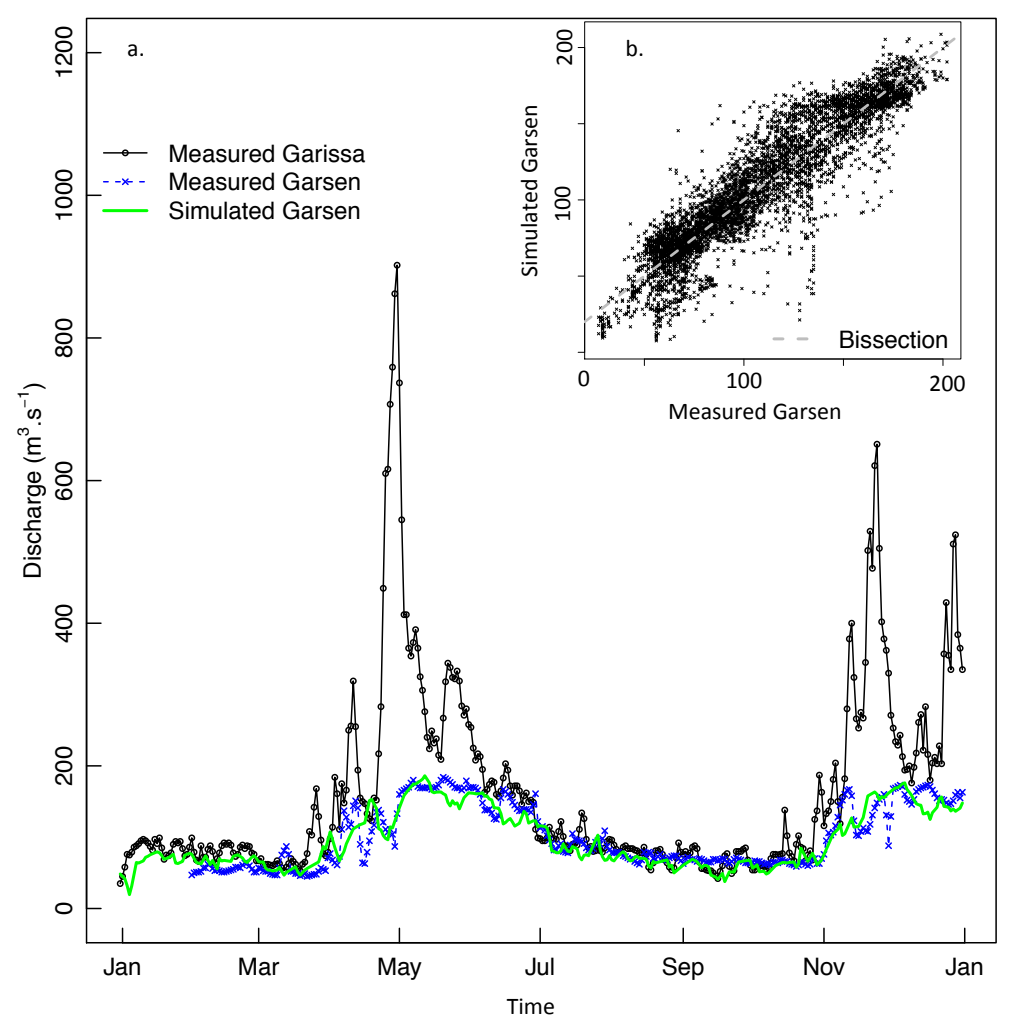

Fig. 2. (a) Example of measured discharges at Garissa, $Q_{1}$, and Garsen, and simulated discharge at Garsen, $Q_{2}$, in 1988 . (b) Simulated versus measured discharge at Garsen for the validation periods (1963-1986 and 1991-1998).

Table 1. Mean water flow per season (and 1 standard deviation) at each station and the resulting water volume ratio between the stations. The number of seasons $(\mathrm{Nb})$ used and the periods considered for each calculation are specified. Each year was divided into two hydrological seasons (1 March-31 August and 1 September29 February) to better use the available data. Seasons with more than $20 \%$ of missing data were excluded (10 seasons for Garissa for 1941-2009; 60 for Garsen for 1951-1998). The remaining missing data, $2.3 \%$ (542 days) and 6.0\% (397 days) for Garissa and Garsen, respectively, were filled in by linear interpolation.

\begin{tabular}{lcrc}
\hline Station & Water flow & $\mathrm{Nb}$ & Period \\
\hline Garissa $\left(\mathrm{km}^{3}\right)$ & $2.51 \pm 1.34$ & 115 & $1941-2009$ \\
Garsen $\left(\mathrm{km}^{3}\right)$ & $1.56 \pm 0.46$ & 23 & $1951-1992$ \\
\hline Volume ratio & $0.76 \pm 0.28$ & 22 & $1951-1992$ \\
\hline
\end{tabular}

delta are also provided by the Tana Delta Irrigation Project (TDIP, $2^{\circ} 316^{\prime} 22.07^{\prime \prime} \mathrm{S}, 40^{\circ} 11^{\prime} 00.55^{\prime \prime} \mathrm{E}$ ). Monthly precipitation data (from the KMD) are available from Garissa. Local precipitation most likely does not induce the floods but instead acts as a "wetting" event before the arrival of the flood wave. Precipitation is low in the semi-arid zones surrounding the delta. With an annual precipitation similar to that in Garissa (373 $\pm 202 \mathrm{~mm} \mathrm{yr}^{-1}, 1962-2008$; KMD) and a low topographical gradient, overland flow and regional groundwater flows to the floodplains are most likely limited, compared to the water brought by the Tana River.

The mean temperature in the delta (1998-2009, TDIP) is $28^{\circ} \mathrm{C}$, with a mean maximum and minimum of $31^{\circ} \mathrm{C}$ in March and $26^{\circ} \mathrm{C}$ in July, respectively, suggesting high evaporation rates over the flooded areas, in accordance with regional monthly values $\left(150-210 \mathrm{~mm} \mathrm{month}^{-1}\right.$, Woodhead, 1968).

Within the delta itself, the main soil types encountered are deep, well drained, dark brown and cracking vertisols and fluvisols (Japan International Cooperation Agency, 1984a,b). The clayey nature of the floodplain soils most likely limits the infiltration of water within the floodplains during flood events. Ground water recharge could occur through infiltration at the sandier locations within the TRD, but quantitative data are unavailable.

Freely available digital elevation models (DEM), e.g. ASTER and SRTM, exist for the whole basin. However, the low resolution of these models relative to the measurements of the altitude makes them inappropriate for hydrological modelling in the flat floodplains of the TRD (the slope gradient from the delta inlet to the estuary is approximately $0.3 \%$ ).

Finally, numerous satellite products (LANDSAT, SPOT, MODIS, radar products) are available at different spatial and 
a.

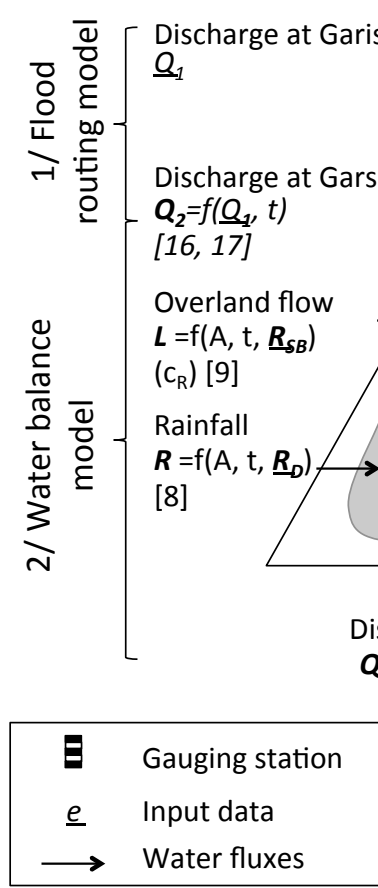

b.

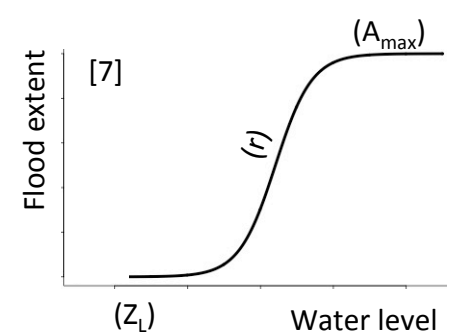

Evapotranspiration

$E=f(A, t, \underline{e})$

[11]

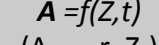

$\left(A_{\max }, r, Z_{L}\right)$

[4]

Infiltration

$I=f(A, t)$
$\left(c_{1}\right)[12]$

Fig. 3. (a) Schematic representation of the Tana Inundation Model. (b) Logistic equation type relating flood extent $A$ to water level $Z$ in the delta. $Q_{1}, Q_{2}$ and $Q_{3}$ : discharges at Garissa, Garsen and the delta outlet; $t$ : time; $R, R_{\mathrm{D}}$ and $R_{\mathrm{SB}}$ : rainfall over the flooded area, at TDIP and at Garissa; $L$ : overland flow; $E$ : evapotranspiration over the flooded area; $e$ : potential evapotranspiration; $I$ : infiltration from the flooded area; $c_{\mathrm{R}}, A_{\max }, r, Z_{\mathrm{L}}, c_{\mathrm{I}}, \alpha, \beta$, and $Z_{\mathrm{SL}}$ are model parameters defined in Table 3.

temporal scales. However, a high cloud cover limits the use of many of those in the optical spectral range, while the overpass frequency of current radar products is too low to obtain a time series of flood extents.

The limited availability of hydrological, climate and topographical data makes the characterization of the flood events within the delta challenging. The rapid analysis of the discharge data suggests that downstream discharge rates can be reconstructed using those at Garissa but that peak discharge attenuation and delay time, as well as the decrease in the discharge rates, are important and hence need to be modelled. Within the delta itself, many water fluxes are ungauged while the DEMs are not precise enough to be used in hydrological studies. Therefore, a water balance model was used to quantify these fluxes, and the flood extents extracted from the medium temporal and spatial resolution remote-sensing products were used to calibrate the model in the absence of other data.

\section{Approach: satellite data analysis and hydrological model specification}

\subsection{Strategy}

To characterize flooded extents in the context of limited data, we constructed a tailor-made hydrological model, the Tana Inundation Model (TIM, Fig. 3). It first reconstitutes river discharge at the delta inlet and then performs a water balance within the delta, taking into account the main water fluxes (river discharges, rainfall, surface flow, evaporation and infiltration). In the absence of topographical data, a logistic equation related the water level within the delta with the flood extent. Calibrated parameters and their associated uncertainties were calculated by comparing these flood extents with those measured from the MODIS satellite data. The temporal dynamics of the floods in the TRD throughout the past decade were simulated with an estimation of the flood extent, duration and frequency. A yearly water balance was also calculated. Finally, the MODIS MYD09A1 products also generated a spatial representation of the flooded zones. The data used in this study are listed in Table 2, and each step of the analysis (Fig. 4) is further explained below. 


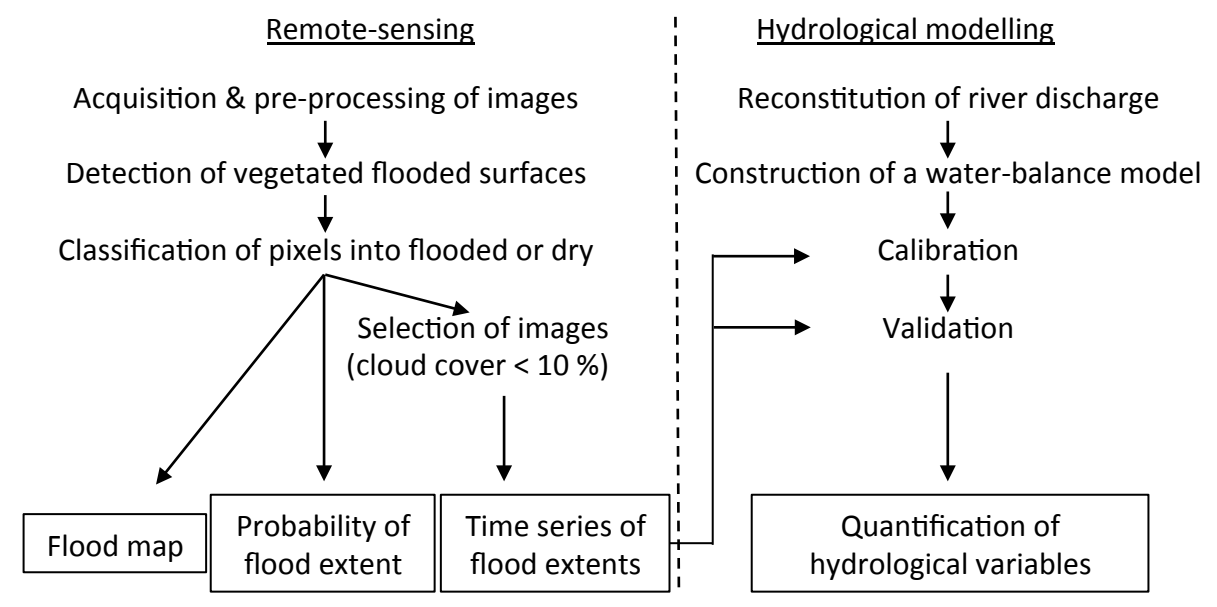

Fig. 4. Workflow diagram.

Table 2. Hydrological, climate and remote sensing data used in the Tana Inundation Model (2002-2011).

\begin{tabular}{lll}
\hline Data & Time step & Use \\
\hline Discharge at Garissa $^{1}$ & daily & Flood propagation \\
MYD09A1 (76 images) $^{2}$ & 8-day composite & Calibration/validation \\
MYD09A1 (434 images) $^{2}$ & 8-day composite & Empirical probabilities \\
Rainfall at Garissa $^{3}$ & monthly & Surface inflow \\
Rainfall at Garsen $^{3}$ & daily & Rainfall inflow \\
Potential evapotranspiration $^{4}$ & monthly & Evaporation \\
\hline
\end{tabular}

Sources: ${ }^{1}$ WRMA; ${ }^{2}$ Nasa; ${ }^{3}$ KMD; ${ }^{4}$ Woodhead, 1968.

\subsection{Analysis of MODIS MYD09A1 product}

\subsubsection{Acquisition and pre-processing of images}

The MYD09A1 500m, 8-day composite images (tile H22V09) were downloaded from the NASA website (434 images from 4 July 2002 to 19 December 2011). All pixels with a high aerosol quantity or a MOD35 cloud cover (indices extracted from the surface reflectance state quality layer) in the visual or mid-infrared bands (bands 2 and 5) were masked (LDOPE software tool, MODIS Land quality assessment group: Roy et al., 2002). The processed images were then reprojected into geographical coordinates, subset to the studied area (upper left corner: $2^{\circ} 6^{\prime} 0^{\prime \prime} \mathrm{S}$, $39^{\circ} 59^{\prime} 56.4^{\prime \prime} \mathrm{E}$, lower right corner: $2^{\circ} 6^{\prime} 0^{\prime \prime} \mathrm{S}, 39^{\circ} 59^{\prime} 56.4^{\prime \prime} \mathrm{E}$ ) and transformed into geotiffs (HDF-EOS To GeoTIFF Conversion Tool, HEG v2.11, EOS, 2012).

Image analysis was carried out on the deltaic floodplains, excluding the river mouth, mangroves and coastal forests. The geographical mask used was constructed manually through a visual interpretation of the $90 \mathrm{~m}$ Shuttle Radar Topography Mission Digital Elevation Model (SRTM DEM). Its contours roughly follow the Menjila-Lamu road to the north, the eastern and western terraces and the southern coastal forest and sand dunes (Fig. 1).

\subsubsection{Detection of vegetated flooded pixels}

Differences in the spectral signature of the land and water covers are used to distinguish the water bodies from the other surfaces. Many water indices have been developed using different spectral bands and different satellite data (Gao, 1996; McFeeters, 1996; Rogers and Kearney, 2004; Xu, 2006) and are commonly used to differentiate land cover types.

A major characteristic of the TRD is the frequent presence of a dense and low-lying vegetation cover above the water. Water indices do not always distinguish between the flooded and non-flooded vegetation. However, Oliesak (2008) used the Modified Normalized Difference Water Index (Xu, 2006) to map the open water bodies in the Inner Niger Delta and the Normalized Difference Water Index of Gao (NDWI ${ }_{\mathrm{Gao}, \mathrm{M} 2-5}$ ) (Gao, 1996) to include the vegetated water. Despite large differences in spatial extent between the Inner Niger Delta and the TRD, some main characteristics of the wetlands (flooded vegetation of Echinochloa stagnina (Retz) P. Beauv) are identical. We therefore used $\mathrm{NDWI}_{\mathrm{Gao}, \mathrm{M} 2-5}$ to map flood extents in the TRD.

$\mathrm{NDWI}_{\mathrm{Gao}, \mathrm{M} 2-5}$ for each pixel was calculated as

$\mathrm{NDWI}_{\mathrm{Gao}, \mathrm{M} 2-5}=\frac{\rho_{\text {red }}-\rho_{\mathrm{MIR}}}{\rho_{\text {red }}+\rho_{\mathrm{MIR}}}$,

where $\rho_{\text {red }}$ and $\rho_{\text {MIR }}$ are the radiances (in reflectance units) in the red and mid-infrared spectral ranges, extracted from bands $2(841-876 \mu \mathrm{m})$ and $5(1230-1250 \mu \mathrm{m})$ of the MYD09A1 product.

To determine the index threshold that best differentiated between the flooded and dry areas, 1398 reference GPS points corresponding to $500 \mathrm{~m}$ by $500 \mathrm{~m}$ flooded or dry zones were manually acquired (Garmin eTrex Legend) on foot or by boat during two flood events (May 2010 and December 2011) and one rainy season when no floods occurred (May 2009) and were compared to the spatially and temporally coincident MYD09A1 pixels. These binary data 
were used to construct error matrices for $\mathrm{NDWI}_{\mathrm{Gao}, \mathrm{M} 2-5}$ values ranging from 0.05 to 0.12 (at a step of 0.01 ). The $\mathrm{NDWI}_{\mathrm{Gao}, \mathrm{M} 2-5}$ value that maximized the percent of correctly classified pixels (i.e. the overall accuracy of Congalton, 1991) was retained as the threshold value. During the classification process, the misclassification of pixels in a flooded (resp. dry) state can be measured (the user's accuracy of Congalton, 1991) and was used here to estimate an uncertainty range for the resulting flood extents, $A_{o}$.

\subsubsection{Classification of pixels and image analysis}

Each pixel within the geographical mask was classified as flooded when its $\mathrm{NDWI}_{\mathrm{Gao}, \mathrm{M} 2-5}$ value was higher than this threshold value (and vice versa), or as clouded. The resulting MODIS imagery set was analyzed in three ways.

First, the empirical probability of flooded state, $p_{i}$, for each pixel, $i$, was calculated as

$p_{i}=\frac{n_{\mathrm{F}, i}}{N_{\mathrm{T}}-n_{\mathrm{c}, i}}$,

where $n_{\mathrm{F}, i}$ is the number of times the pixel $i$ was classified as flooded, $N_{\mathrm{T}}$ is the number of images available and $n_{\mathrm{c}, i}$ is the number of times that the pixel was classified as clouded at band 2 and band 5. This term expresses the fraction of times a pixel was classified in a flooded state, considering the observations of the pixel when it was classified as nonclouded. $p_{i}$ was calculated for each pixel within the study site, and based on these calculations, we then drew an isocontours map of $p_{i}$.

Secondly, a discrete time series of flood extents was obtained from the images presenting less than $10 \%$ cloud cover for all seven bands. Flood extent $A_{o}$ was calculated as

$A_{o}=\gamma \cdot n_{\mathrm{F}}$,

where $\gamma$ is the area of a MODIS pixel $\left(0.216 \mathrm{~km}^{2}\right)$, and $n_{\mathrm{F}}$ is the number of pixels classified in a flooded state. Then, to obtain uncertainty boundaries, 1000 numerical simulations, following a random sampling with replacement design, were undertaken for each image and each of the three classes. The probabilities that each selected pixel had been correctly classified (in a flooded or dry state or in a flooded state but clouded) were taken, respectively, as the user's accuracy for the flooded and dry classes from the error matrix and the ratio of pixels classified as flooded on pixels classified as nonclouded. The upper and lower uncertainty boundaries were then calculated as the 90th and 10th percentiles from the simulations centered around the previously calculated flooded area, so that a maximum $A_{o, x}$ and minimum $A_{o, m}$ flooded area were calculated for each image. Due to the non-random spatial distribution of the GPS data points, this method was only used to estimate the uncertainty range (for which the error is considered negligible as the cloud cover of the selected images was less than $10 \%$ ) and not to calculate flood extents, for which a better estimate can be obtained from Eq. (3).
Lastly, the images were used to obtain an empirical probability of flood extent $p$ using Eq. (3):

$p=\frac{n_{\mathrm{S}}}{N_{\mathrm{T}}}$

where $n_{\mathrm{S}}$ is the number of times the flood extent $A_{o}$ was observed. To estimate $A_{o}$, we considered that a zone subject to floods could be defined $\left(p_{i}>0.01\right)$, and that within this zone, clouds were randomly distributed so that the ratio of flooded to non-flooded area was identical to this same ratio in the clouded areas. Hence $A_{o}$ was estimated as

$A_{o}=\gamma \cdot n_{\mathrm{F}} \cdot\left(1+\frac{n_{\mathrm{c}}}{n_{\mathrm{T}}-n_{\mathrm{c}}}\right)$,

where $n_{\mathrm{c}}$ is number of pixels classified as clouded within the zone subject to floods and $n_{\mathrm{T}}$ is the number of pixels (2105 pixels) of the zone subject to floods within the studied zone (4789 pixels). In order to have a good estimation of the ratio, images where over $50 \%$ of the zone subject to floods was classified as clouded were excluded (96 images).

\subsection{The Tana Inundation Model}

\subsubsection{General structure}

The Tana Inundation Model (TIM, Fig. 3) was composed of a non-linear flood routing model chained to a water balance model within the delta.

Input data were daily discharge rates at Garissa, $Q_{1}$ $\left[\mathrm{L}^{3} \mathrm{~T}^{-1}\right]$, daily precipitation at TDIP, $R_{\mathrm{D}}\left[\mathrm{L} \mathrm{T}^{-1}\right]$, monthly precipitation at Garissa, $R_{\mathrm{SB}}\left[\mathrm{LT}^{-1}\right]$, and monthly potential evapotranspiration rates $e\left[\mathrm{~L} \mathrm{~T}^{-1}\right]$ for the delta (Woodhead, 1968). Gaps in the $Q_{1}$ record were filled by linear interpolation, except for two periods when flood events occurred (5 May 2003-31 October 2003 and 31 March 2005-4 August 2005) for which this method is inappropriate. All results therefore exclude these periods. A 10-day moving average, which was more appropriate for the flood-routing model (Lamagat et al., 1993; Bader et al., 2003), was then used as the model input. State variables were daily discharge rates $Q_{2}$ at the delta inlet, daily discharge rates $Q_{3}$ at the delta outlet, daily evapotranspiration, infiltration and precipitation over the flooded area, $E, I$ and $R$, daily overland flow $L$ from the sub-basin between Garsen and the estuary, and daily flood extent $A\left[\mathrm{~L}^{2}\right]$ within the delta. All fluxes are expressed in $\left[\mathrm{L}^{3} \mathrm{~T}^{-1}\right]$.

Once calibrated and validated, the model provided a time series of flood extents for 2002-2011, as well as the number of flood peaks, their mean duration and flood frequency. Finally, a mean yearly water balance for the delta provided estimations of main water inflows and outflows.

\subsubsection{Flow propagation within the river stretch}

Discharge measurements, $Q_{2}$, were reconstructed using a flood routing model (Lamagat et al., 1993) that has been used 
to model many large rivers with overflow in Africa (Lamagat et al., 1993; Bader et al., 2003; Belaud et al., 2010). This approach relies on a theoretical analysis of the diffusive wave equation and takes into account differences in propagation trends in low and high flow regimes.

According to this method, two empirical relationships were established between the upstream and downstream discharges $\left(Q_{1}\right.$ and $\left.Q_{2}\right)$, and between the upstream station and a delay time, $T$. Calibration of the two empirical relations was performed with a subset of $Q_{1}$ and $Q_{2}$ discharge data (1 December 1986 to 29 June 1991). Upstream and downstream hydrographs were divided into 20 elementary intervals (Belaud et al., 2010), and then, a linear regression was performed between the discharge rates from the two stations for different delay times, $T$, and for each interval. The delay time $T$ was chosen to minimize the root mean square error (RMSE) of the linear regression, thus maximizing the correlation between $Q_{1}$ and $Q_{2}$. Due to scarce data, the empirical $Q_{1}-Q_{2}$ relationship did not have the expected increasing trend at low discharges and was manually corrected. These relationships were then modelled with linear, secondorder polynomial or logarithmic equations, by maximizing $R^{2}$ to obtain continuous functions relating $Q_{1}, Q_{2}$, and $T$. Discharge $Q_{2}$ was calculated as the resulting 10-day moving average daily discharge.

The Nash-Sutcliffe coefficient (NS), the absolute maximum error (AME), the RMSE, and the mean absolute error (MAE), as defined by Dawson (2007), were calculated for $Q_{2}$ for both the calibration (1986-1991) and validation (1963-1986 and 1991-1998) periods to assess the quality of the flood routing model.

\subsubsection{Equations and specifications of the water balance model}

The TRD was represented as a single reservoir, within which a daily water balance was calculated:

$\frac{\mathrm{d} V}{\mathrm{~d} t}=A \cdot \frac{\mathrm{d} Z}{\mathrm{~d} t}=Q_{2}+R+L-Q_{3}-E-I$

where $V\left[\mathrm{~L}^{3}\right], Z[\mathrm{~L}]$ are the volume and the level of water within the reservoir.

In the absence of topographical data, the flooded area $A$ was related to water level $Z$ using a logistic equation:

$A=\frac{A_{\max }}{1+a \cdot \exp ^{-r \cdot Z}}$,

where $A_{\max }$ is the maximum flood extent, while $a[-]$ and $r$ $\left[\mathrm{L}^{-1}\right]$ determine the shape of the logistic curve.

Rainfall input, $R$, was calculated as

$R=R_{\mathrm{D}} \cdot A$,

where $R_{\mathrm{D}}$ is the daily precipitation at TDIP [ $\left.\mathrm{LT}^{-1}\right]$. In the absence of daily precipitation data from 1 March 2007 to
31 December $2007, R_{\mathrm{D}}$ was uniformly distributed daily values calculated from the monthly precipitation data.

Overland flow, $L$, was calculated as a function of rainfall at Garissa, $R_{\mathrm{SB}}$ :

$L=c_{\mathrm{R}} \cdot R_{\mathrm{SB}} \cdot\left(A_{\mathrm{SB}}-A\right)$,

with $c_{\mathrm{R}}$ being the runoff coefficient $[-]$ and $A_{\mathrm{SB}}\left[\mathrm{L}^{2}\right]$ being the sub-basin area after Garsen $\left(13700 \mathrm{~km}^{2}\right)$. In the absence of daily precipitation data for the sub-basin, $R_{\mathrm{SB}}$ was uniformly distributed daily values calculated from the monthly precipitation data at Garissa.

The outflow, $Q_{3}$, which is unknown in reality because of its diffuse character, was related to the level of the water stored above the reservoir's outlet at sea level, $Z_{\mathrm{SL}}[\mathrm{L}]$, in a classical manner, in other words:

$Q_{3}=\alpha \cdot\left(Z-Z_{\mathrm{SL}}\right)^{\beta}$.

$Z-Z_{\mathrm{SL}}$ represents the head loss between the reservoir and its outlet. $\alpha\left[\mathrm{L}^{3-\beta} \mathrm{T}^{-1}\right]$ and $\beta[-]$ are the two parameters of the equation. The value of $\beta$ is typically between a minimum of 0.5 for a Chezy- or Manning-type flow and 1.5 for a free weir flow (Chow, 1959), which is what would be expected here.

Evaporation was calculated in the same way as Wolski et al. (2006):

$E=e \cdot A$.

In the absence of more precise data, uniformly distributed values of daily potential evapotranspiration, $e\left[\mathrm{~L} \mathrm{~T}^{-1}\right]$, were obtained from monthly estimates at Malindi (Woodhead, 1968).

Infiltration was expressed through a linear relationship relating it to the flooded area, $A$ :

$I=c_{\mathrm{I}} \cdot A$,

where $c_{\mathrm{I}}$ is the infiltration rate $\left[\mathrm{L} \mathrm{T}^{-1}\right]$.

The model was coded under R ( $\mathrm{R}$ Development Core Team, 2008) and verified by checking the closure of the water balance for all parameter sets retained in the calibration process. The minimum flooded area $A_{\min }$ was set to $1 \mathrm{~km}^{2}$, and the maximal water level was set to $10 \mathrm{~m}$ to keep the reservoir shape conforming to the TRD. $a$ was calculated from Eq. (7) using the area of permanent lakes $A_{\mathrm{L}}\left(4 \mathrm{~km}^{2}\right)$ and the three parameters $Z_{\mathrm{L}}, A_{\max }$ and $r$. Initial flood extent was set to $A_{\mathrm{L}}$ because the model was initiated at low flow. When the flood extent was minimal, evapotranspiration and infiltration were considered to be negligible. Equation (6) was solved iteratively using the fourth-order Runge-Kutta algorithm (Atkinson, 1989). For reasons of numerical stability, it was solved at an hourly time step. Final output variables were averaged over 10 days so that the temporal resolution was close to that of the MODIS images and major input variables. 
a. Estimation of flood extent

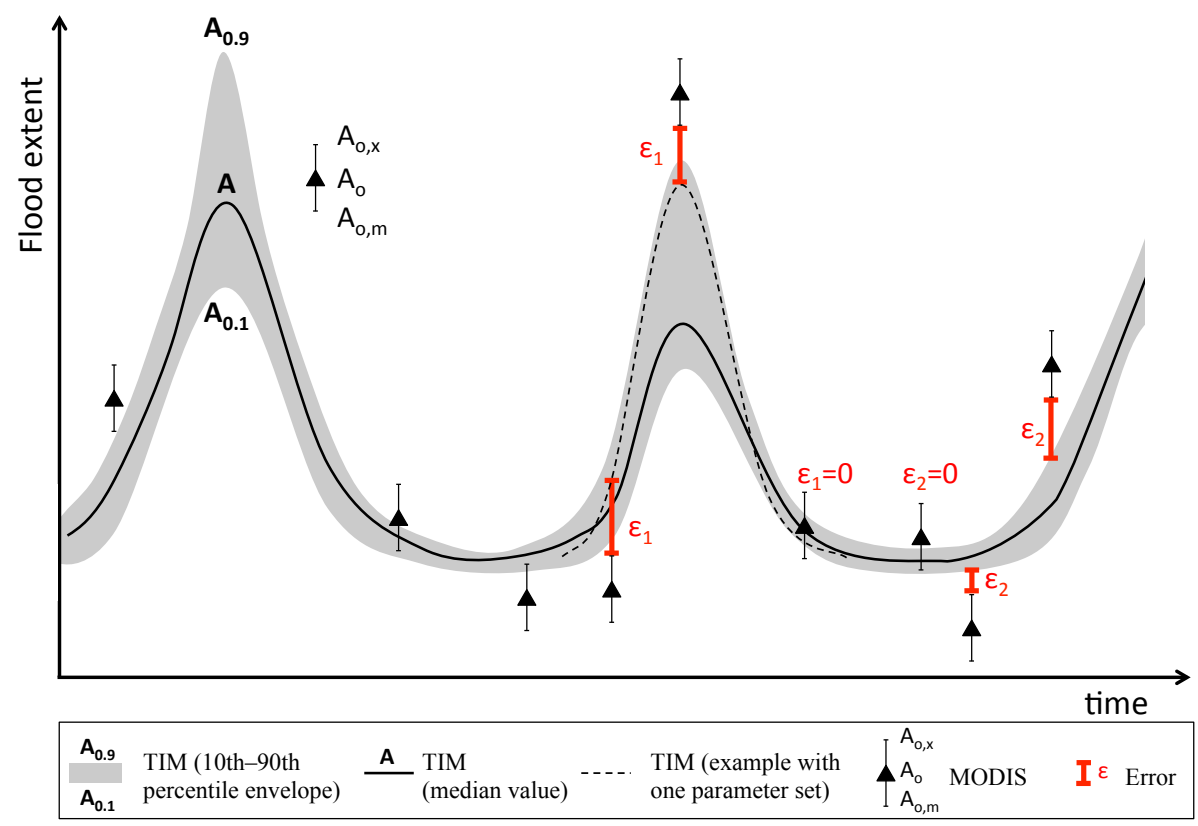

Fig. 5. (a) Simplified scheme depicting the flood extents from TIM and MODIS. (b) Definition of the error $\epsilon_{1}$ and $\epsilon_{2}$.

\subsection{Calibration and validation strategy for the water balance model}

Calibration and validation of hydrological models are usually performed by comparing the simulated data with an independent set of data. Classical evaluation metrics include NS, AME, MAE and RMSE (Table 4). The water balance model had eight parameters (Table 3), which were estimated according to the equifinality concept (Beven and Binley, 1992). This concept states that the uncertainty related to parameter estimations allows for multiple parameter sets to reproduce the observed behavior of a system. This uncertainty needs to be quantified in the modelling procedure (Beven and Binley, 1992) because it affects the interpretation of the model.

In this study, we were interested in (1) selecting parameter sets during a calibration process, then validating each set, and (2) assessing the final quality of the model, which includes the ensemble of parameter sets. In the first case, point simulations were to be compared to an uncertainty range issued from the MODIS images, whilst in the second case, two uncertainty ranges were to be compared. To do so, we defined an evaluation metric $\mathcal{L}_{\epsilon}$ as

$$
\mathcal{L}_{\epsilon}=1-\frac{\sum \epsilon^{2}}{\sum\left(A_{o}-\bar{A}_{o}\right)^{2}},
$$

where $\epsilon$ (Fig. 5) is the error defined in Eq. (14) or Eq. (15), $A_{o}$ is the flooded area observed at each date and $\bar{A}_{o}$ is the mean flooded area from the MODIS images. The likelihood $\mathcal{L}_{\epsilon}$ differs from the Nash-Sutcliffe coefficient because it compares flood extents rather than discharges and differs in the definition of the error $\epsilon$. The latter is the difference between the value measured by MODIS and that simulated by TIM, taking into account the uncertainty ranges. In the calibration and validation of each parameter set, $\epsilon$ was defined between the value from TIM and the uncertainty range from MODIS, so that

If $A<A_{o, m}$ then $\epsilon_{1}=A_{o, m}-A$

If $A_{o, m} \leq A \leq A_{o, x}$ then $\epsilon_{1}=0$

If $A>A_{o, x}$ then $\epsilon_{1}=A-A_{o, x}$.

In the quality assessment phase, $\mathcal{L}_{\epsilon}$ was defined using not only the uncertainty range of the MODIS data, but also the uncertainty range of TIM as the equifinality concept states that all selected parameter sets are acceptable. Hence, $\epsilon$ becomes as follows:

If $A_{0.9}<A_{o, m}$ then $\epsilon_{2}=A_{o, m}-A_{0.9}$

If $A_{o, m} \leq A_{0.9}$ and $A_{0.1} \leq A_{o, x}$ then $\epsilon_{2}=0$

If $A_{0.1}>A_{o, x}$ then $\epsilon_{2}=A_{0.1}-A_{o, x}$,

where $A_{0.1}$ and $A_{0.9}$ are the 10th and 90th percentile boundaries for the calibrated hydrological model. The advantage of this approach is that it increases the flexibility in the calibration process for a model that needs to be constrained using a very limited amount of data.

Model calibration was performed using the Generalized Likelihood Uncertainty Estimation (GLUE) methodology (Beven and Binley, 1992; Beven and Freer, 2001). Ranges 
Table 3. Definition of water balance model parameters.

\begin{tabular}{llll}
\hline Parameter & Signification & Range/value & Unit \\
\hline$\alpha$ & parameter for discharge $Q_{3}$ & $0-10 \mathrm{E} 6$ & $\mathrm{~m}^{3-\beta}$ day $^{-1}$ \\
$\beta$ & parameter for discharge $Q_{3}$ & $0.2-1.7$ & - \\
$A_{\max }$ & maximum flooded area & $300-700$ & $\mathrm{~km}^{2}$ \\
$r$ & parameter for logistic equation & $1-40$ & $\mathrm{~m}^{-1}$ \\
$c_{\mathrm{R}}$ & overland runoff coefficient & $0-0.05$ & - \\
$c_{\mathrm{I}}$ & infiltration rate & $0-25^{*}$ & $\mathrm{~mm} \mathrm{day}-1$ \\
$Z_{\mathrm{L}}$ & water level of permanent lakes & $0-2$ & $\mathrm{~m}$ \\
$Z_{\mathrm{SL}}$ & water level at outlet & $0-5$ & $\mathrm{~m}$ \\
\hline
\end{tabular}

* Parameter range from Clapp and Hornberger (1978).

were fixed for the model parameters (Table 3), and the parameter sets were randomly generated within these bounds, using a uniform distribution. The model was then run with each parameter set, and the results that did not meet our acceptance criteria were rejected. A first selection was conducted by retaining the sets yielding a $\mathcal{L}_{\epsilon}>0.60$ and a full solution of the differential equation (Eq. 6). Secondly, the parameter sets were further restrained to reproduce the observed conditions (a flood extent higher than $150 \mathrm{~km}^{2}$ on 31 May 2010 or lower than $10 \mathrm{~km}^{2}$ in May 2009).

This parameter selection was performed using a splitsample approach. The time series was separated into two periods (1 January 2002-21 September 2006 and 22 September 2006-31 December 2011), each of which was used for the selection of a limited number of parameter sets. The initial pool consisted of 200000 sets of parameters for each period. Finally, both reduced sets were combined, and the uncertainty ranges were defined by the 90th and 10th quantiles obtained from the likelihood-weighted output variables.

Each parameter set was validated by calculating the evaluation metrics $\left(\mathcal{L}_{\epsilon_{1}}, \mathrm{AME}_{\epsilon}, \mathrm{MAE}_{\epsilon}, \mathrm{RMSE}_{\epsilon}\right.$, with the error defined from $\epsilon_{1}$ ) from the data not used during the calibration process. In the final assessment of the quality of the water balance model, including the ensemble of parameter sets, $\mathcal{L}_{\epsilon_{2}}, \mathrm{AME}_{\epsilon}, \mathrm{MAE}_{\epsilon}, \mathrm{RMSE}_{\epsilon}$ were calculated for 2002-2011, with the error defined from $\epsilon_{2}$.

\section{Results}

\subsection{Satellite data}

The overall accuracy of the pixel classification was maximal $(92.63 \%)$ at $\mathrm{NDWI}_{\mathrm{Gao}, \mathrm{M} 2-5}=0.09$ (Table 5). The overall accuracy always exceeded $85 \%$ for all the $\mathrm{NDWI}_{\mathrm{Gao}, \mathrm{M} 2-5}$ values between 0.05 and 0.012 , showing that the index was not sensitive within this range.

Seventy-six images (Fig. 6) were characterized by a cloud cover of less than $10 \%$. The resulting set was welldistributed between the rainy and dry seasons. The maximum and minimum flood extents were $0-6 \mathrm{~km}^{2}$ and $302-316 \mathrm{~km}^{2}$ (10th and 90th percentiles). Only 19 images presented a flood extent over $100 \mathrm{~km}^{2}$.
Table 4. Evaluation metrics used for the calibration or validation steps of the water balance model. $\epsilon$ is defined in either Eqs. (14) or (15). $A_{o}$ : flood extent measured from the MODIS imagery; $\bar{A}_{o}$ : mean flood extent from MODIS imagery; $n$ : number of concurrent TIM and MODIS observations.

\begin{tabular}{lll}
\hline Metric & Abbreviation & Equation \\
\hline Likelihood & $\mathcal{L}_{\epsilon}$ & $1-\frac{\sum \epsilon^{2}}{\sum\left(A_{o}-\bar{A}_{o}\right)^{2}}$ \\
Absolute maximum error & $\operatorname{AME}_{\epsilon}$ & $\max |\epsilon|$ \\
Mean absolute error & $\operatorname{MAE}_{\epsilon}$ & $\frac{1}{n} \sum|\epsilon|$ \\
Root mean square error & $\operatorname{RMSE}_{\epsilon}$ & $\sqrt{\frac{1}{n} \sum \epsilon^{2}}$ \\
\hline
\end{tabular}

The contours of the preferential flooding zones, which are derived from the empirical probability of flooded state $p_{i}$, are mapped in Fig. 7. The size of the area with an empirical probability $p_{i}$ exceeding 0.01 was $450 \mathrm{~km}^{2}$. The maximum empirical probability of flooded state was 0.41 in the south-eastern part of the delta, corresponding to a zone under tidal influence. The flooded zones mainly followed the active Matomba branch of the river and then spread out within the floodplain grasslands. On the contrary, zones surrounding the formerly active Oda branch were rarely flooded. The major lakes of the zone (Moa, Shakababo and Bilissa Boka lakes) were visible. Furthermore, ancient channels surrounded by riverine forests and other non-flooded zones effectively appeared to be dry. As expected, villages were out of the flooded zones, but close to them for easy access to pasture and farming land. The map corroborates well with our knowledge of the terrain.

\subsection{TIM}

\subsubsection{Calibration and validation of the flood-routing model}

The model reproduces the observed discharges at the Garsen station to a satisfactory degree, with reasonable NS, RMSE, AME and MAE for both the calibration and validation periods (Table 6).

The discharge at Garsen $\left(Q_{2}, \mathrm{~m}^{3} \mathrm{~s}^{-1}\right)$ and the time delay ( $T$, day) are described by Eqs. (16) and (17):

$$
\begin{aligned}
& \text { If } Q_{1} \in[0,320] \text { then } Q_{2}(t)=-0.0014 \cdot Q_{1}^{2}(t-T) \\
& +0.9557 \cdot Q_{1}(t-T) \\
& \text { If } Q_{1}>320 \text { then } Q_{2}(t)=0.04692 \cdot Q_{1}(t-T)+145.69(16)
\end{aligned}
$$

The resulting curves are typical of an overflowing river with a very low slope. Downstream discharge increased with 


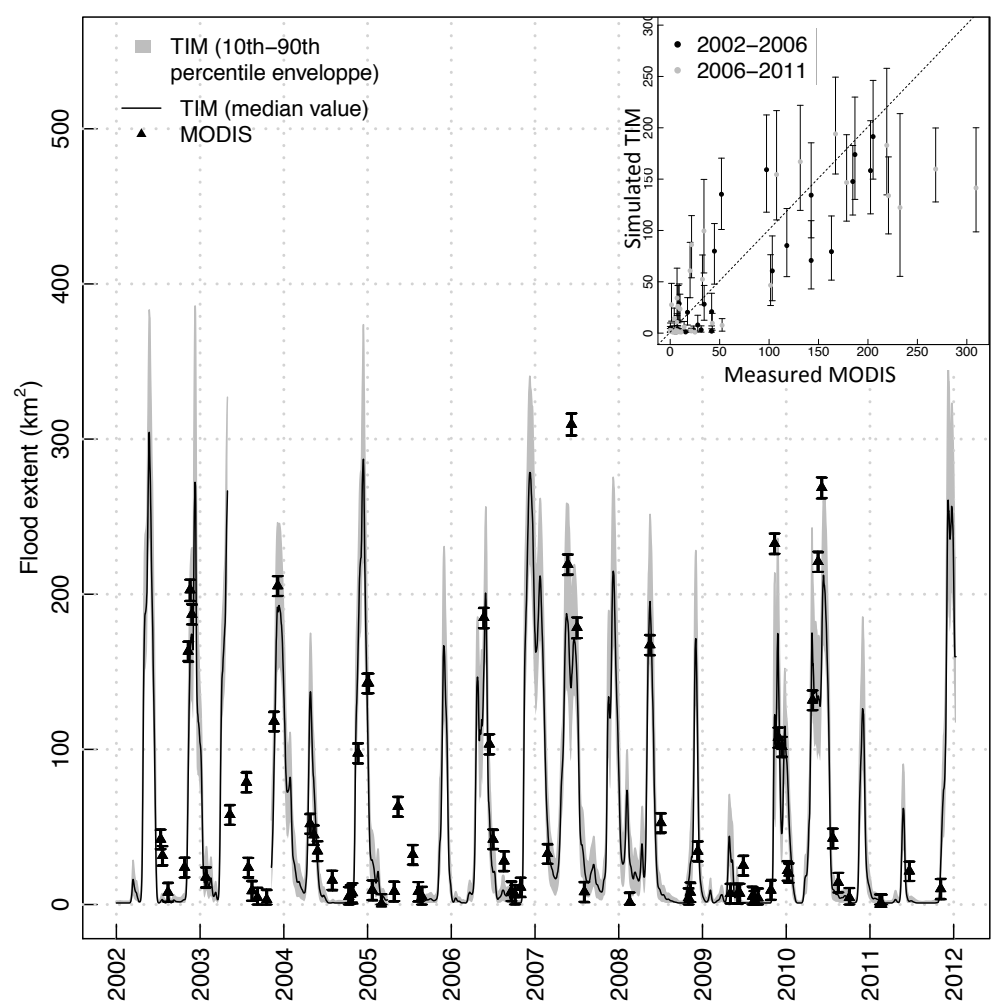

Fig. 6. Flood extent in the delta for 2002-2011, as computed by TIM or measured from the MODIS imagery.

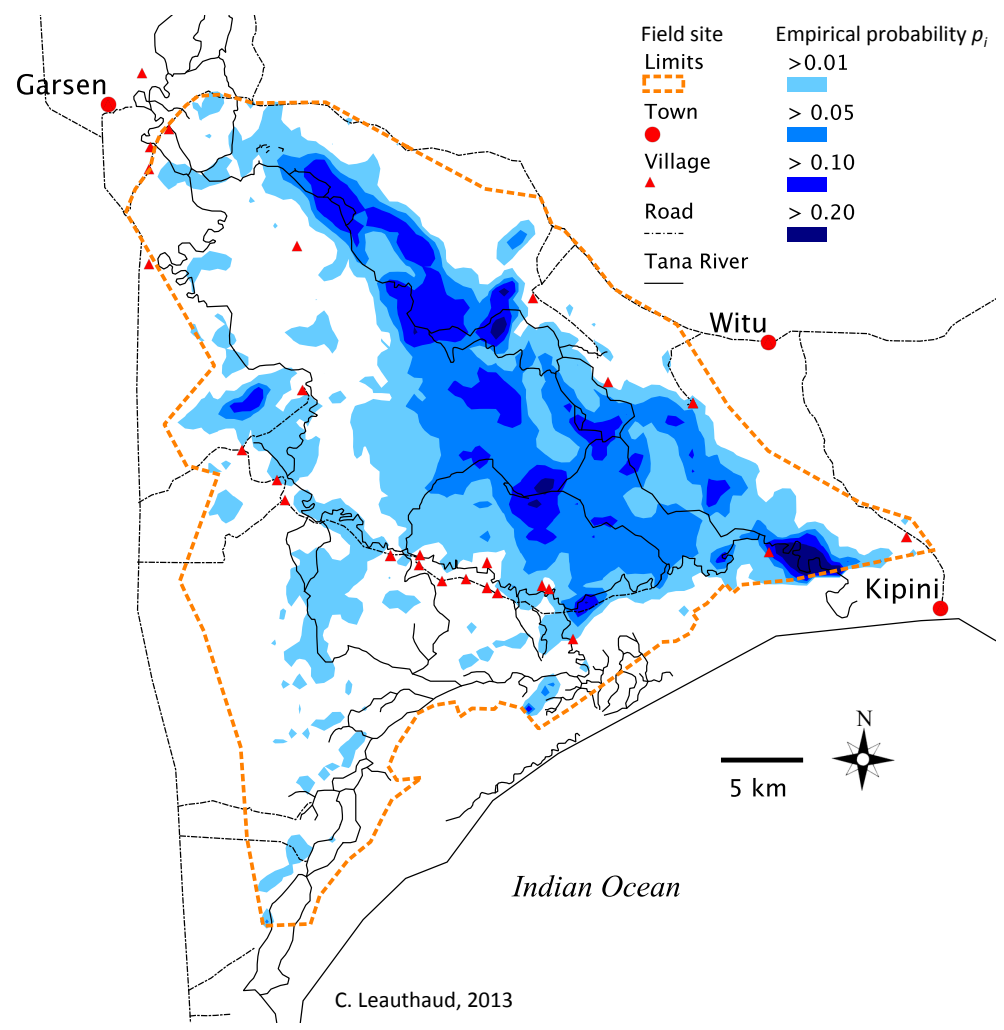

Fig. 7. Map of the iso-contours of empirical probability of flooded state, extracted from the MODIS images (2002-2011). 
Table 5. Number of correctly classified MODIS pixels at three different dates, compared to the total number of groundtruthing points (Nb) in a dry or flooded state, for different $\mathrm{NDWI}_{\mathrm{Gao}, \mathrm{M} 2-5}$ values. The resulting user's and overall accuracy are given.

\begin{tabular}{|c|c|c|c|c|c|c|c|c|c|c|}
\hline \multirow[t]{2}{*}{ Date } & \multicolumn{2}{|c|}{ Groundtruthing data } & \multicolumn{8}{|c|}{$\mathrm{NDWI}_{\mathrm{Gao}, \mathrm{M} 2-5}$ threshold value } \\
\hline & State & $\mathrm{Nb}$ & 0.05 & 0.06 & 0.07 & 0.08 & 0.09 & 0.10 & 0.11 & 0.12 \\
\hline 25 May 2009 & dry & 410 & 407 & 409 & 409 & 410 & 410 & 410 & 410 & 410 \\
\hline 25 May 2010 & dry & 270 & 167 & 186 & 213 & 230 & 244 & 255 & 261 & 264 \\
\hline 19 December 2011 & dry & 253 & 196 & 226 & 238 & 245 & 246 & 248 & 249 & 251 \\
\hline 25 May 2010 & flooded & 211 & 195 & 191 & 185 & 183 & 181 & 175 & 170 & 163 \\
\hline 19 December 2011 & flooded & 254 & 238 & 233 & 230 & 224 & 214 & 207 & 196 & 179 \\
\hline User's accuracy (\%) & dry & & 96.0 & 95.3 & 94.5 & 93.9 & 92.2 & 91.7 & 90.3 & 88.3 \\
\hline User's accuracy (\%) & flooded & & 72.7 & 79.1 & 85.0 & 89.5 & 92.3 & 95.0 & 96.5 & 97.7 \\
\hline Overall accuracy (\%) & & & 86.1 & 89.1 & 91.2 & 92.4 & 92.6 & 92.6 & 92.0 & 90.6 \\
\hline
\end{tabular}

Table 6. NS, RMSE, AME and MAE values for the calibration (1986-1991) and validation (1963-1986 and 1991-1998) periods of the flood routing model.

\begin{tabular}{lcccc}
\hline Period & $\begin{array}{c}\text { NS } \\
(-)\end{array}$ & $\begin{array}{c}\text { RMSE } \\
\left(\mathrm{m}^{3} \mathrm{~s}^{-1}\right)\end{array}$ & $\begin{array}{c}\text { AME } \\
\left(\mathrm{m}^{3} \mathrm{~s}^{-1}\right)\end{array}$ & $\begin{array}{c}\text { MAE } \\
\left(\mathrm{m}^{3} \mathrm{~s}^{-1}\right)\end{array}$ \\
\hline Calibration & 0.89 & 14 & 74 & 10 \\
Validation & 0.87 & 16 & 107 & 12 \\
\hline
\end{tabular}

upstream discharge. At high discharges, the slope of Eq. (16) decreased due to overflowing into the floodplains and the consequent evaporation. At high discharges, $Q_{1}$, time-delay $T$ increased as water overflowed into the large floodplains. According to the model, a flood of $500 \mathrm{~m}^{3} \mathrm{~s}^{-1}$ required approximately 12 days to reach Garsen from Garissa.

\subsubsection{Calibration and validation of the water balance model}

Calibrated parameters are presented in Table 3. They did not reveal any structure within the prior distribution space. However, $Z_{\mathrm{L}}$ and $Z_{\mathrm{SL}}$ were highly correlated (0.84), $r$ and $\alpha$ showed a correlation of 0.44 , and $\alpha$ and $\beta$ showed a correlation of 0.37 . The correlations (absolute values) between the other parameters were all less than 0.24 (and mostly less than 0.1). The correlation between $Z_{\mathrm{L}}$ and $Z_{\mathrm{SL}}$ was high because the water level within the delta is always higher than that at the outlet.

During the 2002-2006 calibration period, 462 sets of parameters were selected using the GLUE approach (Table 7). The likelihood, $\mathcal{L}_{\epsilon_{2}}$, was of 0.91 and 0.83 for the calibration and validation periods. During the 2006-2011 calibration period, 72 sets of parameters were selected (Table 7). $\mathcal{L}_{\epsilon_{2}}$ was 0.73 and 0.89 for the calibration and validation periods, respectively. The model seems better adapted to the 2002-2006 period, which has more parameter sets and higher $\mathcal{L}_{\epsilon_{2}}$ values compared to 2006-2011. After further restriction, 112 parameter sets were finally retained. The global model
Table 7. Evaluation metrics of the water balance model, for the calibration and validation periods and for 2002-2011. Error $\epsilon$ is defined in Eqs. (14) or (15).

\begin{tabular}{lcrrrrr}
\hline $\begin{array}{l}\text { Calibration/ } \\
\text { Validation }\end{array}$ & Period & $\mathrm{Np}^{*}$ & $\begin{array}{r}\mathrm{AME}_{\epsilon} \\
\left(\mathrm{km}^{2}\right)\end{array}$ & $\begin{array}{r}\mathrm{MAE}_{\epsilon} \\
\left(\mathrm{km}^{2}\right)\end{array}$ & $\begin{array}{r}\mathrm{RMSE}_{\epsilon} \\
\left(\mathrm{km}^{2}\right)\end{array}$ & $\begin{array}{c}\mathcal{L}_{\epsilon} \\
(-)\end{array}$ \\
\hline Calibration & $2002-2006$ & 462 & 72.7 & 10.8 & 20.7 & 0.91 \\
Calibration & $2006-2011$ & 72 & 161.2 & 27.0 & 45.5 & 0.73 \\
\hline Validation & $2002-2006$ & 72 & 80.6 & 13.1 & 23.9 & 0.89 \\
Validation & $2006-2011$ & 462 & 143.5 & 21.5 & 35.9 & 0.83 \\
Validation & $2002-2011$ & 112 & 102.2 & 9.2 & 20.4 & 0.93 \\
\hline
\end{tabular}

* Np: number of selected parameter sets. Parameter sets selected in the calibration period 2002-2006 were validated in the period 2006-2011 and vice-versa.

performance for each period and the entire 2002-2011 period are summarized in Table 7. $\mathcal{L}_{\epsilon_{2}}, \mathrm{AME}_{\epsilon}$ and $\mathrm{MAE}_{\epsilon}$ were, respectively, $0.93,102 \mathrm{~km}^{2}$ and $9 \mathrm{~km}^{2}$ for the entire period. In light of these criteria, the proposed model performed well.

Finally, a water balance for each selected parameter set was computed. The median total volume of water transiting through the system was $28.9 \pm 0.5 \mathrm{~km}^{3}$. A mean absolute difference of $0.86 \%$ between the incoming and outgoing fluxes for all of the parameter sets was observed and attributed to the approximations of the numerical resolution. This difference is considered negligible.

\subsection{Quantification of hydrological variables}

Flood extents simulated by TIM for 2002-2011 are represented in Fig. 6. They corroborated well with the flood extents calculated from the MODIS imagery. The periodicity of the floods was well reproduced, with floods occurring during the rainy seasons. According to the hydrological model, the maximum flood peaks of the past decade occurred in May and December 2002, with median and 90th percentile values of 304 and $383 \mathrm{~km}^{2}$, and 272 and $385 \mathrm{~km}^{2}$, respectively. On the contrary, the floods of May 2011 seem to have been negligible $\left(<100 \mathrm{~km}^{2}\right)$. The last fact was confirmed in the field. 
Table 8. Number of floods and their mean duration (days) for 2002-2011.

\begin{tabular}{|c|c|c|c|c|c|c|}
\hline \multirow[t]{2}{*}{ Flood extent } & \multicolumn{2}{|c|}{ 10th percentile } & \multicolumn{2}{|c|}{ Median } & \multicolumn{2}{|c|}{ 90th percentile } \\
\hline & $\mathrm{Nb}$ & Duration & $\mathrm{Nb}$ & Duration & $\mathrm{Nb}$ & Duration \\
\hline$>100 \mathrm{~km}^{2}$ & 17 & $27 \pm 19$ & 16 & $43 \pm 25$ & 17 & $50 \pm 25$ \\
\hline$>200 \mathrm{~km}^{2}$ & 5 & $11 \pm 4$ & 9 & $18 \pm 11$ & 15 & $28 \pm 20$ \\
\hline$>300 \mathrm{~km}^{2}$ & 0 & 0 & 1 & 6 & 5 & $19 \pm 6$ \\
\hline
\end{tabular}

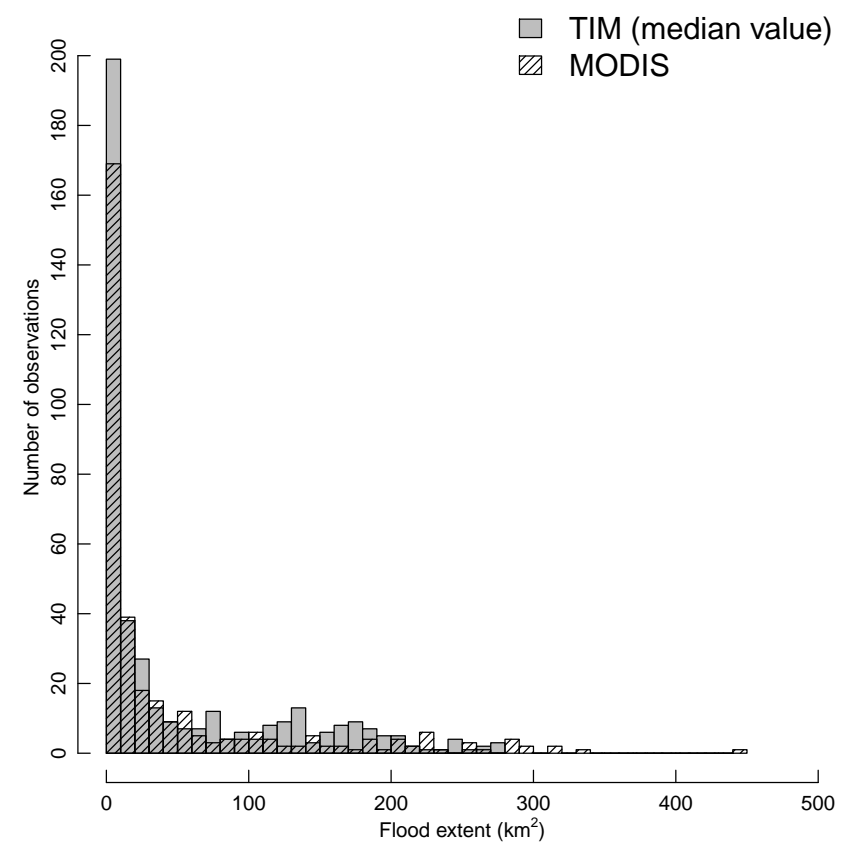

Fig. 8. Histogram of flood extents calculated from the TIM and MODIS images. Counts were conducted every eight days. Total numbers of counts were 413 and 338 for TIM and MODIS, respectively.

Sixteen flood events with flood peaks over $100 \mathrm{~km}^{2}$ (median value) were recorded for 2002-2011 (Table 8). Their duration was 43 days (median value). Among these floods, four lasted less than 20 days. These events were quite regular, with floods over $100 \mathrm{~km}^{2}$ lasting more than 20 days occurring for over $2 / 3$ of the rainy seasons. However, because of the calibration procedure of TIM, small flood extents could be overestimated.

Flood events of a larger scale were more rare, with a median number of nine flood events over $200 \mathrm{~km}^{2}$ for the 18 recorded potential flooding periods. These floods occurred on average once a year, even though there are two potential flooding seasons per year. Their mean median and 90th percentile durations were $18 \pm 11$ days and $28 \pm 20$ days, respectively, with the longest 90th percentile flood durations of 45 and 82 days having taken place in May 2002 and December 2007, respectively. Flood events over $300 \mathrm{~km}^{2}$ were recorded 0 to 3 times and were of short duration.
Table 9. Annual water flows $\left(\mathrm{km}^{3} \mathrm{yr}^{-1}\right)$, calculated from the median values of TIM.

\begin{tabular}{lccc}
\hline Flow & 2002-2011 & $2009^{2}$ & $2007^{3}$ \\
\hline Total discharge $Q_{2}$ & 3.17 & 2.54 & 3.90 \\
Total rainfall $R$ & 0.06 & 0.04 & 0.10 \\
Total overland flow $L$ & 0.09 & 0.08 & 0.09 \\
\hline Total inflow $\left(Q_{2}+R+L\right)$ & 3.32 & 2.66 & 4.09 \\
\hline Total discharge $Q_{3}$ & 2.95 & 2.53 & 3.49 \\
Total evapotranspiration $E$ & 0.11 & 0.04 & 0.20 \\
Total infiltration $I$ & 0.22 & 0.09 & 0.39 \\
\hline Total outflow $\left(Q_{3}+E+I\right)$ & 3.28 & 2.66 & 4.08 \\
\hline${ }^{1}$ mean; ${ }^{2}$ minimum value; ${ }^{3}$ maximum value. & & &
\end{tabular}

For the whole 2002-2011 period, flood extent was lower than $10 \mathrm{~km}^{2} 48 \%$ of the time (Fig. 8) while flood extents over 100 and $200 \mathrm{~km}^{2}$ were observed 22 and $4 \%$ of the time. These results corroborate with the empirical probability of flood extent calculated from the MODIS imagery (Fig. 8).

An empirical relationship relating the flood extent $A$ with the incoming discharge $Q_{2}$ was also obtained from the TIM (Fig. 9). Confidence intervals (median values of the 10th and 90th percentiles of each data point) were calculated. Only three floods corresponding to extreme rainfall events do not fall within these intervals. Floods exceeding $100 \mathrm{~km}^{2}$ occurred for discharges higher than $130 \mathrm{~m}^{3} \mathrm{~s}^{-1}$ (median value of the 50th percentile of each data point). An increase of $30 \mathrm{~m}^{3} \mathrm{~s}^{-1}$ resulted in floods of nearly $200 \mathrm{~km}^{2}$.

Finally, the annual water balances were calculated for 2002-2011 using the median values of the parameter ensemble (Table 9). The total input discharge, rainfall, overland flow, output discharge, evapotranspiration and infiltration flows calculated in the water balance are represented in Fig. 10. Mean annual water inflow into the delta was approximately $3.3 \mathrm{~km}^{3} \mathrm{yr}^{-1}$. The minimum and maximum yearly inflows were observed in 2009 and 2007 at 2.7 and $4.1 \mathrm{~km}^{3} \mathrm{yr}^{-1}$, respectively. The river discharges $Q_{2}$ and $Q_{3}$ corresponded to over 95 and $89 \%$, respectively, of the mean annual water inflow.

\section{Discussion and conclusions}

\subsection{Remotely sensed detection of flood extents}

The NDWI $\mathrm{Gao}_{\mathrm{G} 2-5}$ index properly distinguished the flooded surfaces, including the low-lying vegetated flooded zones, from dry surfaces. Furthermore, this index can be calculated from many of the MODIS products, as well as from other optical sensors, such as LANDSAT, making it a good candidate to monitor flooded surfaces with a low-lying vegetated cover, which is typically found in wetlands. 


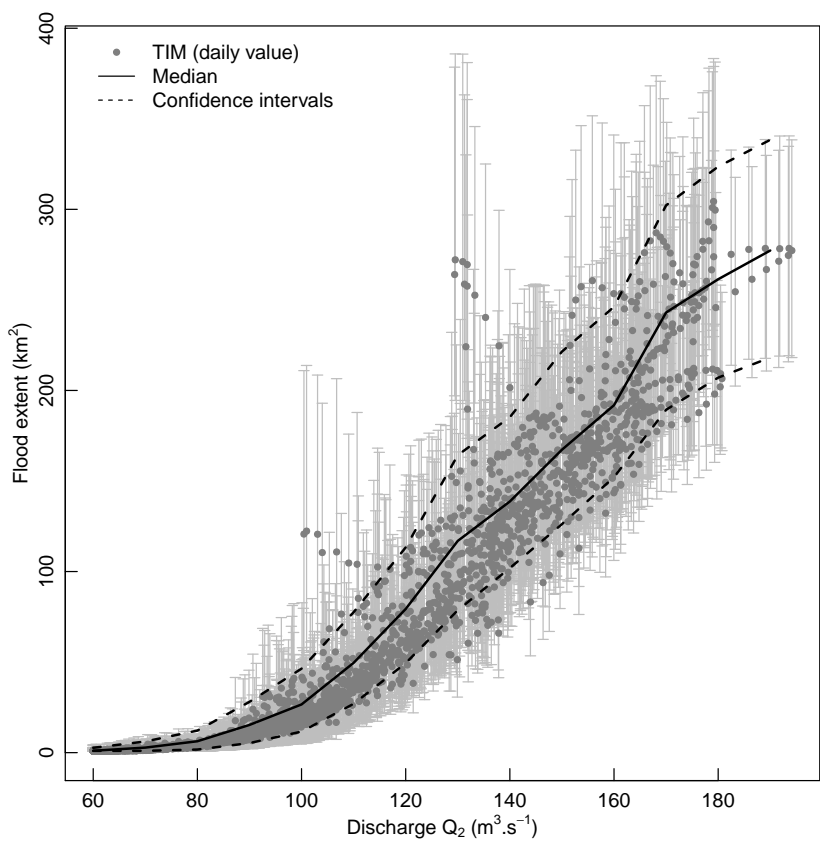

Fig. 9. Relationship between discharge at the delta inlet $Q_{2}$, and flood extent $A$, as computed by TIM. Error bars depict the 10th and 90th percentile values. "Median" and "Confidence intervals" depict the median values calculated from the median, 10th and 90th percentiles of TIM.

The use of the MYD09A1 composite product from the MODIS instruments allowed the characterization of the state of the surface despite a high cloud cover. In particular, it gave the first estimation of the spatial flooding pattern and a time series of flood extents, that are in good agreement with the water balance model. The use of finer-resolution satellite products would improve the estimation of flooded area by decreasing the classification error due to mixed pixels. However, the disadvantages concerning its medium spatial resolution and 8-day uncertainty range are counter-balanced by its availability and high temporal resolution compared to many other satellite products. It can therefore be used in combination with the latter to characterize and monitor floods in medium- to large-scale wetland complexes.

\subsection{The Tana Inundation Model}

The use of a lumped model in combination with satellite data is a first step in quantifying the flooding characteristics in the poorly gauged wetlands of the Tana River Delta. By doing so, this paper contributes to the growing literature on the use of hydrological modelling in ungauged basins and follows previous recommendations to use "tailor-made" and "sitespecific" models (Savenije, 2009).

The water balance approach adopted here was relevant to study the TRD system, for which information on the internal properties and processes were limited. The downscaling of rainfall and evaporation from monthly to daily data was justified as these flows account for only a small part of the water balance. The global fluxes generating floods and the flooding characteristics in the deltaic floodplains were quantified. These results have relatively high uncertainty ranges linked to the lack of essential data, such as a Digital Elevation Model and the scarcity of recent discharge measurements within the delta. Moreover, because of the chosen evaluation metric, the relative uncertainty for the low inundation extents is larger than for the high values. The model should therefore be better at capturing large flooded areas. Finally, the annual water balance confirms that the river discharge coming from Garissa, and therefore the upper basin, is the major process controlling the flooding events within the Tana River Delta.

In the future, semi-distributed or distributed models could be developed for the TRD. This study helps define which data are essential but unavailable in the zone, so that future research efforts concentrate on the acquisition of such data. Regular discharge or water level measurements at the inlet, outlet and other strategic locations (channel bifurcations, etc.) should be undertaken. A precise topographic map is necessary to describe the volume-area-water level relationships and hence the channel-overland flow dynamics. Lastly, in-situ or satellite measurements of flood extents are essential for parameter estimation and validation of future models.

\subsection{Management issues}

This study determined the major characteristics of flood propagation within the Garissa-Garsen stretch. An understanding of these characteristics is essential for the management of water resources. These characteristics seem to have remained identical throughout 1963-2011, despite the construction of five dams. This finding is particularly interesting in the context of hydroelectric infrastructure development because it supports the idea that dams could have modified the volume of transiting water (Maingi and Marsh, 2002) but not the flood propagation characteristics.

TIM provides an ensemble of flooding characteristics (flood extent, duration, timing, frequency of occurrence) that are essential in flood forecasting. The discharge-flood extent relationship also enables a rapid estimation of flood extents, which is information that can be used to monitor or predict floods in the delta. The MODIS images give complementary information concerning the spatial flooding patterns, which are also crucial for wetland monitoring. These images could be used to define the current flood-prone zones. Finally, this study highlights the idea that river fluxes are the main generator of floods within the delta. This result is important in the current context of hydroelectric infrastructure development on the Tana River.

Together, the results and the model developed in the study can help predict the consequences of the modification of the hydrological regime of the river on flooding events in the delta. Such prediction is essential because many ecosystems 

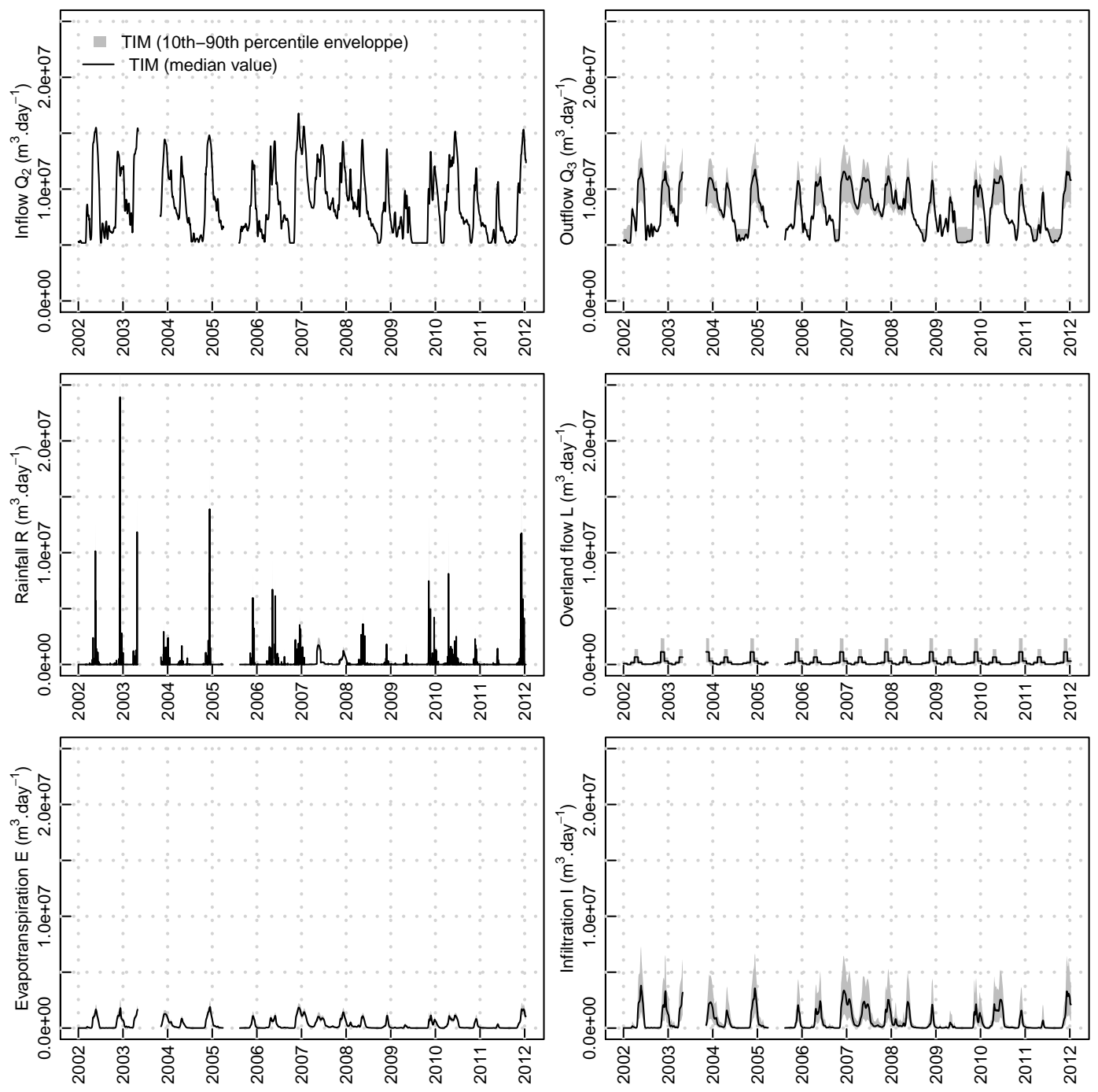

Fig. 10. Simulated total daily discharges $Q_{2}, Q_{3}$, rainfall $R$, overland flow $L$, evapotranspiration $E$, and infiltration $I$ for 2002-2011, as computed by TIM.

and local communities are dependent on the dynamic flooding regime of the Tana River.

Acknowledgements. This project was financed by the French Ministry of Environment in the framework of the project "Eaux et Territoires", by the Research Institute for Development (IRD) and by the LISAH laboratory. We thank the Water Resource Management Authority for providing the discharge data, the Kenya Department of Meteorology and the Tana Delta Irrigation Project for the rainfall data. The National Museums of Kenya (NMK), the People, Livestock and the Environment (PEL) research group at the International Livestock Research Institute (ILRI) in Nairobi and the IRD representation in East Africa are acknowledged. We also thank the anonymous reviewers for their useful comments and J.-S. Bailly for our discussions on error matrices.

\section{References}

Alsdorf, D. E., Rodriguez, E., and Lettenmaier, D. P.: Measuring surface water from space, Rev. Geophys., 45, RG2002, doi:10.1029/2006RG000197, 2007.

Atkinson, K. E.: An Introduction to Numerical Analysis, John Wiley \& Sons, New York, 1989.

Bader, J., Lamagat, J., and Guiguen, N.: Management of the Manantali Dam on the Senegal River: quantitative analysis of a conflict of objectives, Hydrolog. Sci. J. - Journal des Sciences Hydrologiques, 48, 525-538, doi:10.1623/hysj.48.4.525.51415, 2003.

Barbier, E. and Thompson, J.: The value of water: Floodplain versus large-scale irrigation benefits in Northern Nigeria, Ambio, 27, 434-440, 1998.

Edited by: B. Schaefli 
Belaud, G., Cassan, L., Bader, J., Bercher, N., and Feret, T.: Calibration of a propagation model in large river using satellite altimetry, in: 6th International Symposium on Environmental Hydraulics, 23-25 June 2010, Athens, 2010.

Beven, K. and Binley, A.: The future of distributed models: Model calibration and uncertainty prediction, Hydrol. Process., 6, 279298, doi:10.1002/hyp.3360060305, 1992.

Beven, K. and Freer, J.: Equifinality, data assimilation, and uncertainty estimation in mechanistic modelling of complex environmental systems using the GLUE methodology, J. Hydrol., 249, 11-29, doi:10.1016/S0022-1694(01)00421-8, 2001.

Chow, V. T.: Open-channel hydraulics, McGraw-Hill, New York, $1-680,1959$.

Clapp, R. B. and Hornberger, G. M.: Empirical equations for some soil hydraulic properties, Water Resour. Res., 14, 601-604, 1978.

Congalton, R. G.: A review of assessing the accuracy of classifications of remotely sensed data, Remote Sens. Environ., 37, 35-46, 1991.

Daily, G. (Ed.): Nature's Services: Societal Dependence On Natural Ecosystems, Island Press, Washington, D.C., 1997.

Dawson, C. W., Abrahart, R. J., and See, L. M.: HydroTest: A web-based toolbox of evaluation metrics for the standardised assessment of hydrological forecasts, Environ. Model. Softw., 22, 1034-1052, doi:10.1016/j.envsoft.2006.06.008, 2007.

Duvail, S. and Hamerlynck, O.: Mitigation of negative ecological and socio-economic impacts of the Diama dam on the Senegal River Delta wetland (Mauritania), using a model based decision support system, Hydrol. Earth Syst. Sci., 7, 133-146, doi:10.5194/hess-7-133-2003, 2003.

Duvail, S. and Hamerlynck, O.: The Rufiji River flood: plague or blessing?, Int. J. Biometeorol., 52, 33-42, 2007.

Duvail, S., Médard, C., Hamerlynck, O., and Nyingi, D. W.: Land and Water Grabbing in an East African Coastal Wetland: The Case of the Tana Delta, Water Alternativ., 5, 322-343, 2012.

EOS: HDF-EOS To GeoTIFF Conversion Tool (HEG), http: //newsroom.gsfc.nasa.gov/sdptoolkit/HEG/HEGHome.html (last access: 27 July 2013), 2012.

Feng, L., Hu, C., Chen, X., Cai, X., Tian, L., and Gan, W.: Assessment of inundation changes of Poyang Lake using MODIS observations between 2000 and 2010, Remote Sens. Environ., 121, 80-92, 2012.

Gao, B.: NDWI - A normalized difference water index for remote sensing of vegetation liquid water from space, Remote Sens. Environ., 58, 257-266, doi:10.1016/S0034-4257(96)00067-3, 1996.

Hamerlynck, O., Luke, Q., Nyange, T., Duvail, S., and Leauthaud, C.: Range Extension, Imminent Threats and Conservation Options for Two Endangered Primates: the Tana River Red Colobus Procolobus rufomitratus rufomitratus (Peters, 1879) and the Tana River Mangabey Cercocebus galeritus (Peters, 1879) in the Lower Tana Floodplain and Delta, Kenya, African Primates, Nairobi, 7, 211-217, 2012.

Hunter, N. M., Bates, P. D., Horritt, M. S., and Wilson, M. D.: Simple spatially-distributed models for predicting flood inundation: a review, Geomorphology, 90, 208-225, 2007.

Islam, A. S., Bala, S. K., and Haque, M. A.: Flood inundation map of Bangladesh using MODIS time-series images, J. Flood Risk Manage., 3, 210-222, doi:10.1111/j.1753-318X.2010.01074.x, 2010.
Japan International Cooperation Agency: Vegetation and present land-use map - Garsen, Japan International Cooperation Agency/Survey of Kenya/Kenya Soil Survey, Tokyo, Japan, Map Y731A 179/3, 1984a.

Japan International Cooperation Agency: Vegetation and present land-use map - Witu, Japan International Cooperation Agency/Survey of Kenya/Kenya Soil Survey, Tokyo, Japan, Map Y731A 179/4, 1984b.

Lamagat, J. P., Morel-Seytoux, J., and Albergel, J.: Analyse de la propagation des ondes de crue, Hydrol. Continent., 8, 113-137, 1993.

Lamagat, J. P., Sambou, S., and Albergel, J.: Analyse statisitque de l'écoulement d'un fleuve dans une plaine d'inondation: application aux cotes maximales du fleuve Niger dans le cuvette lacustre, in: L'hydrologie tropicale: géoscience et outil pour le développement: mélanges à la mémoire de Jean Rodier, IAHS Press, Wallingford, UK, p. 238, 1996.

Leauthaud, C.: Diagnostic agraire dans le delta du Tana, au Kenya, M.S., AgroParisTech, Paris, France, 2009.

Leauthaud, C., Duvail, S., Hamerlynck, O., Paul, J.-L., Cochet, H., Nyunja, J., Albergel, J., and Grünberger, O.: Floods and livelihoods: The impact of changing water resources on wetland agroecological production systems in the Tana River Delta, Kenya, Global Environ. Change, 23, 252-263, 2013.

Leblanc, M., Lemoalle, J., Bader, J. C., Tweed, S., and Mofor, L.: Thermal remote sensing of water under flooded vegetation: New observations of inundation patterns for the 'Small' Lake Chad, J. Hydrol., 404, 87-98, doi:10.1016/j.jhydrol.2011.04.023, 2011.

Loth, P. (Ed.): The return of the water, Restoring the Waza Logone Floodplain in Cameroon, IUCN, Gland, Switzerland and Cambridge, UK, 2004.

Mahe, G., Orange, D., Mariko, A., and Bricquet, J. P.: Estimation of the flooded area of the Inner Delta of the River Niger in Mali by hydrological balance and satellite data, in: Hydro-Climatology: Variability and Change, vol. 344 of IAHS Publication, 25th General Assembly of the International Union of Geodesy and Geophysics, 28 June-7 July 2011, Melbourne, Australia, 138-143, 2011.

Maingi, J. and Marsh, S.: Quantifying hydrologic impacts following dam construction along the Tana River, Kenya, J. Arid Environ., 50, 53-79, doi:10.1006/jare.2000.0860, 2002.

McFeeters, S.: The use of the normalized difference water index (NDWI) in the delineation of open water features, Int. J. Remote Sens., 17, 1425-1432, 1996.

Millennium Ecosystem Assessment: Ecosystems and Human Wellbeing: Wetlands and Water synthesis, Tech. rep., World Resources Institute, Washington, D.C., 2005.

Milzow, C., Kgotlhang, L., Bauer-Gottwein, P., Meier, P., and Kinzelbach, W.: Regional review: the hydrology of the Okavango Delta, Botswana-processes, data and modelling, Hydrogeol. J., 17, 1297-1328, doi:10.1007/s10040-009-0436-0, 2009.

Mitsch, W. J. and Gosselink, J.: Wetlands, Wiley, New York, 2000.

Oliesak, A.: Suivi par télédétection de la dynamique de crue du delta intérieur du Niger pour l'élaboration d'un modèle de fonctionnement hydraulique, M.S., Université Paris Diderot, Paris, France, 2008. 
Ordoyne, C. and Friedl, M. A.: Using MODIS data to characterize seasonal inundation patterns in the Florida Everglades, Remote Sens. Environ., 112, 4107-4119, doi:10.1016/j.rse.2007.08.027, 2008.

Prigent, C., Papa, F., Aires, F., Jimenez, C., Rossow, W. B., and Matthews, E.: Changes in land surface water dynamics since the 1990 s and relation to population pressure, Geophys. Res. Lett., 39, L08403, doi:10.1029/2012GL051276, 2012.

R Development Core Team: R: A language and environment for statistical computing, R Foundation for Statistical Computing, Vienna, Austria, 2008.

Republic of Kenya: Kenya Population and Housing Census, Tech. rep., Central Bureau of Statistics, Nairobi, Kenya, 2010.

Rogers, A. and Kearney, M.: Reducing signature variability in unmixing coastal marsh Thematic Mapper scenes using spectral indices, Int. J. Remote Sens., 25, 2317-2335, doi:10.1080/01431160310001618103, 2004.

Roy, D., Borak, J., Devadiga, S., Wolfe, R., Zheng, M., and Descloitres, J.: The MODIS Land product quality assessment approach, Remote Sens. Environ., 83, 62-76, 2002.

Sakamoto, T., Van Nguyen, N., Kotera, A., Ohno, H., Ishitsuka, N., and Yokozawa, M.: Detecting temporal changes in the extent of annual flooding within the Cambodia and the Vietnamese Mekong Delta from MODIS time-series imagery, Remote Sens. Environ., 109, 295-313, doi:10.1016/j.rse.2007.01.011, 2007.

Savenije, H. H. G.: HESS Opinions "The art of hydrology", Hydrol. Earth Syst. Sci., 13, 157-161, doi:10.5194/hess-13-1572009, 2009.

Sippel, S., Hamilton, S., Melack, J., and Novo, E.: Passive microwave observations of inundation area and the area/stage relation in the Amazon River floodplain, Int. J. Remote Sens., 19, 3055-3074, doi:10.1080/014311698214181, 1998.
Ticehurst, C. J., Dyce, P., and Guerschman, J. P.: Using passive microwave and optical remote sensing to monitor flood inundation in support of hydrologic modelling, in: Interfacing modelling and simulation with mathematical and computational sciences, 18th World IMACS/MODSIM Congress, 1317 July 2009, Cairns, Australia, 3747-3753, 2009.

United Nations Development Programme: Kenya National Human Development Report 830 2009, Youth and Human Development: Tapping the Untapped Resource, Tech. rep., United Nations Development Programme, Nairobi, Kenya, 2010.

Vitousek, P., Mooney, H., Lubchenco, J., and Melillo, J.: Human domination of Earth's ecosystems, Science, 277, 494-499, doi:10.1126/science.277.5325.494, 1997.

Wolski, P., Savenije, H. H. G., Murray-Hudson, M., and Gumbricht, T.: Modelling of the flooding in the Okavango Delta, Botswana, using a hybrid reservoir-GIS model, J. Hydrol., 331, 58-72, doi:10.1016/j.jhydrol.2006.04.040, 2006.

Woodhead, T.: Studies of potential evaporation in Kenya, Tech. rep., Water development department, Ministry of Natural Resources, Nairobi, Kenya, 1968.

$\mathrm{Xu}, \mathrm{H}$.: Modification of normalised difference water index (NDWI) to enhance open water features in remotely sensed imagery, Int. J. Remote Sens., 27, 3025-3033, 2006.

Zahar, Y., Ghorbel, A., and Albergel, J.: Impacts of large dams on downstream flow conditions of rivers: Aggradation and reduction of the Medjerda channel capacity downstream of the Sidi Salem dam (Tunisia), J. Hydrol., 351, 318-330, doi:10.1016/j.jhydrol.2007.12.019, 2008. 